\section{RSP}

http://www.rsp.fsp.usp.br/
Revista de Saúde Pública

\title{
Factor associated with self-reported work-related musculoskeletal disorders in Brazilian adults
}

\author{
Ada Ávila Assunção', Mery Natali Silva Abreu" \\ ' Departamento de Medicina Preventiva e Social. Universidade Federal de Minas Gerais. Belo Horizonte, MG, Brasil \\ " Departamento de Enfermagem Aplicada. Universidade Federal de Minas Gerais. Belo Horizonte, MG, Brasil
}

Correspondence:

Ada Ávila Assunção

Programa de Pós-Graduação em

Saúde Pública, Departamento de

Medicina Preventiva e

Social - UFMG

Av. Professor Alfredo Balena, 190,

sala 705 30130-100

Belo Horizonte, MG, Brasil

E-mail: adavila@medicina.ufmg.br

Received: 20 Sep 2016

Approved: 3 Dec 2016

How to cite: Assunção AA, Abreu MNS. Factor associated with self-reported work-related musculoskeletal disorders in Brazilian adults. Rev Saude Publica. 2017;51 Suppl 1:10s.

Copyright: This is an open-access article distributed under the terms of the Creative Commons Attribution License, which permits unrestricted use, distribution, and reproduction in any medium, provided that the original author and source are credited.

\section{ABSTRACT}

OBJECTIVE: To describe the prevalence of work-related musculoskeletal disorder (WMSD) and analyze the factors associated with this outcome in the Brazilian population.

METHODS: In this cross-sectional, population-based study, we use data from the National Survey on Health (PNS) of 2013. The sample was composed of 60,202 Brazilians aged 18 years or older. The outcome variable was the occurrence of self-reported WMSD. Sociodemographic and occupational characteristics, personal resources, and health conditions were investigated as explanatory variables. Analyses were performed with the software Stata 12.0 and considered the weighting imposed by the sampling design of the study. Then, univariate and multivariate binary logistic models were carried out, considering a significance level of 5\%.

RESULTS: The results obtained indicated that the prevalence of WMSD in the Brazilian population was of $2.5 \%$, ranging from $0.2 \%$ (Acre) to $4.2 \%$ (Santa Catarina). The factors associated with a greater chance of occurrence of WMSD were: female sex (OR $=2.33$; 95\%CI 1.72-3.15); be temporarily away from work ( $\mathrm{OR}=2.44 ; 95 \% \mathrm{CI} 1.41-4.23)$; be exposed to noise at the workplace $(\mathrm{OR}=2.16$; $95 \% \mathrm{CI} 1.68-2.77)$; seniority equal to or greater than 4.5 years at the current job $(\mathrm{OR}=1.37$; 95\%CI 1.09-1.72); participate in volunteer work $(\mathrm{OR}=1.65$; $95 \% \mathrm{CI} 1.25-2.17)$; report medical diagnosis of arthritis or rheumatism $(\mathrm{OR}=2.40$; $95 \% \mathrm{CI} 1.68-3.44)$; and depression $(\mathrm{OR}=2.48$; 95\% CI 1.86-3.31). On the other hand, factors associated with less chance of WMSD were: not having a partner $(\mathrm{OR}=0.73$; $95 \% \mathrm{CI} 0.37-0.71)$ and working in an open environment $(\mathrm{OR}=0.51$; 95\% CI 0.37-0.71).

CONCLUSIONS: The associated factors and the prevalence found indicate regional and gender differences. Special attention to comorbidities and environmental noise monitoring would benefit the health of workers in the Country.

DESCRIPTORS: Cumulative Trauma Disorders, epidemiology. Risk Factors. Socioeconomic Factors. Working Conditions. Health Surveys. 


\section{INTRODUCTION}

Work-related musculoskeletal disorders (WMSD) refer to a range of conditions resulting from inflammation or degeneration of tendons, nerves, ligaments, muscles, and periarticular structures in different sites (fingers, wrists, forearms and arms, shoulders, and cervical region) of the upper limbs and neck ${ }^{1,2}$.

The terms used in the literature differ according to the social security legislation in force in each country: repetitive strain injury (RSI), cumulative trauma injuries, work-related nonspecific disorders of the upper limbs, work-related musculoskeletal problems, cervicobrachial syndrome of occupational origin, among others. What those terms have in common is that they designate localized inflammation, nerve compression syndromes, or pain syndromes. For this reason, they are considered umbrella terms ${ }^{2}$. The different existing nominations have already been the subject of publications in the specialized literature ${ }^{3}$.

In 1987, for the first time, Brazil Social Security system recognized this group of disorders with the denomination "typist's tenosynovitis." In 1991, the acronym RSI was adopted in internal procedures of the institution for the assessment of incapacity. In 1998, by the Technical Standard of the National Institute of Health and Social Security (INSS), approved by Service Order INSS/DSS No. 606, of August 5, 1998, formalized the use of WMSD to designate such disorders.

The acronym RSI, in Brazil, has reached the common sense since the social negotiations in the 1980s, by the recognition of the occupational nature of the disorders. Despite having inaccuracies, WMSD is more comprehensive, since symptoms may arise associated with a stress or trauma, and not exclusively due to a repetitive gesture, as suggested by the acronym (RSI) that has become more widespread. It is worth mentioning that environmental factors and tasks that require repetition and stereotyped attitudes are recognized risks.

The progress of the research and the scientific evidence produced in the last three decades is undeniable, as several authors dedicated themselves to identify the factors related to the emergence and evolution of workers' complaints ${ }^{1,2}$. The results are enlightening: they do not derive from sudden injuries, neither from systemic ones, but from low intensity traumas, acting for long periods on normal or altered musculoskeletal structures. Heavy loads can change the tissues when they surpass the physical capacity of response, producing muscle or ligament injury. In its turn, lighter loads, when continuously applied, can cause inflammation, due to the prolonged stretch of the tissues from the structures required by the movement ${ }^{3}$. Its origin is multifactorial and evidence indicating the contribution of the organization of work in the development of these disorders is consistent ${ }^{1,2}$.

In the European Union, musculoskeletal disorders represent 53\% of the total number of occupational diseases recorded, and $50 \%$ of the situations that lead to absences from work for over three days 4 . In the United States, these disorders are responsible for $29 \%$ of all diseases and accidents that lead to work leave ${ }^{5}$.

In Brazil, there are no nationwide data available with fineness of detail. However, prevalence studies allow a rough estimate of the severity of the situation. According to Social Security records, in the last decade, the diagnostic group with higher prevalence of benefits of the sickness leave-type comprised musculoskeletal diseases ${ }^{\mathrm{a}}$.

Much evidence can be found in this regard. For instance, $50 \%$ of bank workers in the city of Pelotas, RS, mentioned having experienced musculoskeletal pain in the past year ${ }^{6}$. Among the steelworkers of the city of Canoas, RS, $75.2 \%$ reported some type of musculoskeletal symptom in the past year ${ }^{7}$. Using the same reference period and questioning about all body segments, the prevalence of musculoskeletal pain in a sample of health workers from the city of Salvador, BA, was $49.9 \%^{8}$. However, there are no known results of population studies. This study proposes to describe the prevalence of WMSD and to analyze the factors associated with this outcome in the Brazilian population. 


\section{METHODS}

\section{Study Design and Data Collection}

This is a cross-sectional study, based on secondary data collected by the National Survey on Health (PNS) ${ }^{\mathrm{b}}$.

The PNS is a household population-based and national level survey, carried out in partnership with the Brazilian Institute of Geography and Statistics (IBGE), from August 2013 to February 2014. It will be part of the Integrated System of Household Surveys (SIPD) of IBGE and shall have a periodicity of 5 years. This survey aims to produce data on the health status and lifestyle of the population of Brazil, as well as to assess access to and use of health services, preventive actions, continuity of care, and financing of health care.

The target population of the PNS is residents of private permanent households, and has all national territory as its demographic scope. PNS used conglomerate sampling in three stages, with stratification of the primary sampling units. The census tracts or set of tracts constitute the primary sampling units; the households were the second-stage units; and residents aged 18 years or older, third-stage units.

PNS 2013 sampling is composed by 64,348 households, in which 60,202 Brazilians aged 18 years or more accepted to answer to the individual questionnaire and, therefore, make up the sample investigated in this study.

\section{Studied Variables}

The outcome of this study was the occurrence of self-reported WMSD, characterized by positive response to the following question: "Has some doctor ever diagnosed you with WMSD (work-related musculoskeletal disorder)?" Age at first diagnosis, treatment used, and the level of limitation of activity due to the disease were also considered in the assessment.

Regarding the factors associated with the occurrence of WMSD, three blocks of variables were analyzed: 1 . sociodemographic characteristics (sex, age, marital status, and education level); 2. occupational characteristics (work paid in money, work paid in products, "odd jobs" or occasional activities, unpaid work, temporary leave from work, time and reason for the leave, numbers of jobs or equivalent) and working conditions (night hours, open or closed environment, exposure to noise, seniority in the current employment); and 3. personal resources and health conditions (participation in sport activities, the neighborhood association, volunteer work, or cults and religious activities, engaging in physical activity, health assessment, report of having been diagnosed with arthritis and depression, use of medication to sleep).

\section{Statistical Analysis}

All analyses were performed with the software Stata 12.0 and considered the weighting imposed by the sampling design of the study.

Initially, a descriptive analysis of all the studied variables was made by calculating relative frequencies and constructing a bar graph. To assess the possible factors associated with the occurrence of WMSD, Pearson's Chi-square test was used, as well as the binary logistic regression model, both univariate and multivariate.

${ }^{\mathrm{b}}$ Instituto Brasileiro de Geografia e Estatística (IBGE). Pesquisa Nacional de Saúde 2013, IBGE. Percepção do estado de saúde, estilo de vida e doenças crônicas. Brasil, Grandes Regiões e Unidades da Federação. Rio de Janeiro: IBGE; 2014.

For the variables to be entered in the multivariate analysis, a p-value of less than 0.20 was considered in the univariate analysis. Models were constructed for each block of variables (sociodemographic characteristics; occupational characteristics, including working conditions; personal resources; health conditions) using the backward method to enter the variables in each block. In the final model of each block remained variables with $\mathrm{p}<$ 0.05 . Then, the final model was adjusted by the variables of all blocks, remaining only those with significant level of $5 \%$. The odds ratio (OR) value were estimated, with $95 \%$ confidence 
interval (95\%CI), both in the univariate and multivariate analyses. The goodness of fit was assessed by Hosmer and Lemeshow statistics.

PNS was approved by the National Research with Human Beings Ethics Committee (Conep - Process: 328.159, on June 26, 2013).

\section{RESULTS}

The prevalence of WMSD in the Brazilian population was of 2.5\% (95\%CI 2.2-2.7), ranging from $0.2 \%$ (Acre) to $4.2 \%$ (Santa Catarina) (Figure). Among the respondents who reported the diagnosis, $25.5 \%$ did physical exercise or physical therapy due to the disease, $35.7 \%$ used WMSD drugs, and 2.6\% did acupuncture. More than half of the respondents reported that the disorders limited their usual activities - for $13.1 \%$ of them this limitation was intense and to $2.8 \%$, very intense. The average age when diagnosed with WMSD was 36.3 years (95\%CI 34.9-37.8).

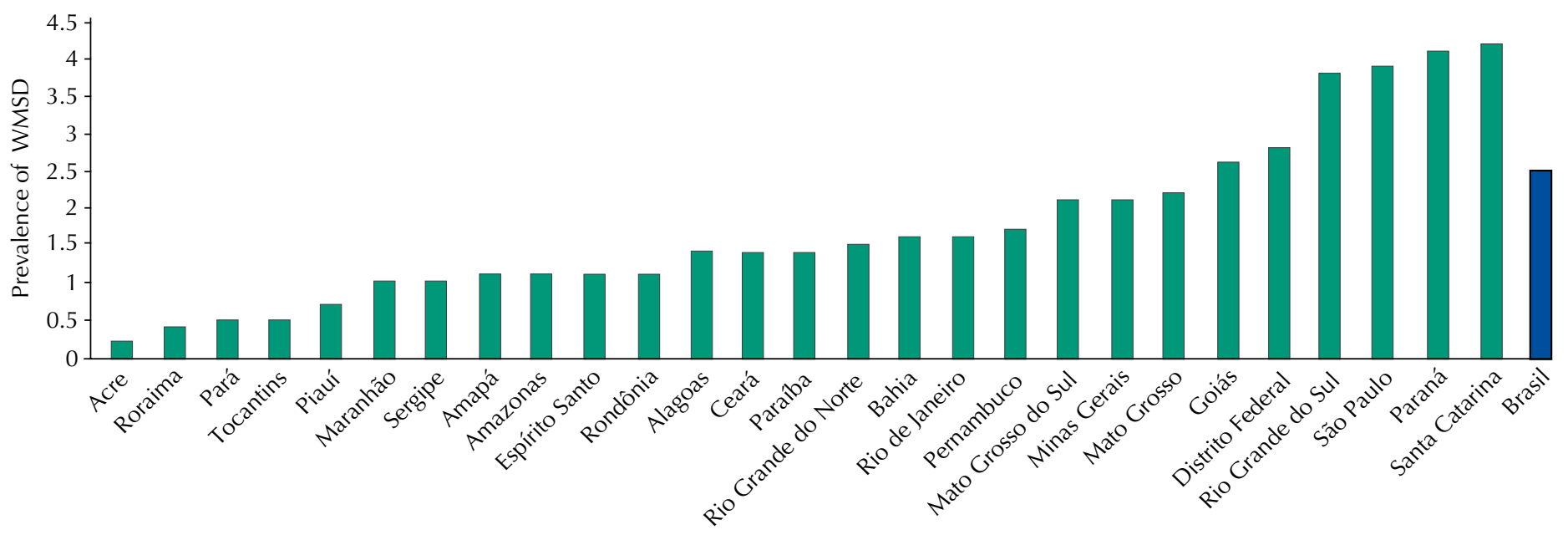

WMSD: work-related musculoskeletal disorders.

Figure. Prevalence of WMSD in the Brazilian population in each of the 26 states and the Federal District, according to data from the PNS, Brazil, 2013.

Table 1. Univariate analysis assessing sociodemographic factors associated with the occurrence of WMSD, according to data from the PNS, Brazil, 2013.

\begin{tabular}{|c|c|c|c|c|c|}
\hline Variable & Percentage $(\%)$ total sample & Prevalence $(\%)$ of WMSD & $\mathrm{p}^{*}$ & OR & $95 \% \mathrm{Cl}$ \\
\hline \multicolumn{6}{|l|}{ Sex } \\
\hline Male & 44.9 & 1.5 & $<0.001$ & 1.00 & \\
\hline Female & 55.1 & 3.3 & & 2.22 & $1.80-2.75$ \\
\hline \multicolumn{6}{|l|}{ Age group (years) } \\
\hline $18-24$ & 14.5 & 1.3 & $<0.001$ & 1.00 & \\
\hline $25-34$ & 21.0 & 2.3 & & 1.78 & $1.11-2.87$ \\
\hline $35-44$ & 19.2 & 3.3 & & 2.59 & $1.63-4.11$ \\
\hline $45-54$ & 18.2 & 3.7 & & 2.93 & $1.85-4.66$ \\
\hline$\geq 55$ & 27.1 & 1.9 & & 1.43 & $0.86-2.37$ \\
\hline \multicolumn{6}{|l|}{ Marital status } \\
\hline Have a partner & 45.1 & 3.0 & $<0.001$ & 1.00 & \\
\hline No partner & 54.9 & 2.1 & & 0.67 & $0.56-0.80$ \\
\hline \multicolumn{6}{|l|}{ Education level } \\
\hline Illiterate/no formal education & 13.9 & 1.7 & $<0.001$ & 1.00 & \\
\hline Elementary school & 35.5 & 2.3 & & 1.41 & $1.01-1.96$ \\
\hline High school & 33.0 & 2.5 & & 1.53 & $1.09-2.14$ \\
\hline Higher education & 17.5 & 3.5 & & 2.18 & $1.48-3.21$ \\
\hline
\end{tabular}

WMSD: work-related musculoskeletal disorders.

* Pearson's Chi-square test. 
Table 2. Univariate analysis assessing occupational characteristics and work conditions associated with the occurrence of WMSD, according to data from the PNS, Brazil, 2013.

\begin{tabular}{|c|c|c|c|c|c|}
\hline Variable & Percentage (\%) total sample & Prevalence (\%) of WMSD & $\mathbf{p}^{\mathrm{a}}$ & OR & $95 \% \mathrm{Cl}$ \\
\hline \multicolumn{6}{|l|}{ Work paid in money } \\
\hline No & 43.2 & 2.1 & 0.005 & 1.00 & \\
\hline Yes & 56.9 & 2.8 & & 1.34 & $1.09-1.64$ \\
\hline \multicolumn{6}{|l|}{ Work paid in products } \\
\hline No & 99.8 & 2.5 & 0.733 & 1.00 & \\
\hline Yes & 0.2 & 3.5 & & 1.42 & $0.19-10.56$ \\
\hline \multicolumn{6}{|l|}{ "Odd jobs" or occasional activities } \\
\hline No & 98.2 & 2.5 & 0.942 & 1.00 & \\
\hline Yes & 1.8 & 2.4 & & 0.97 & $0.48-1.98$ \\
\hline \multicolumn{6}{|l|}{ Unpaid work } \\
\hline No & 99.2 & 2.5 & 0.581 & 1.00 & \\
\hline Yes & 0.8 & 1.9 & & 0.75 & $0.27-2.10$ \\
\hline \multicolumn{6}{|l|}{ Temporary leave from work } \\
\hline No & 98.5 & 2.4 & $<0.001$ & 1.00 & \\
\hline Yes & 1.5 & 9.6 & & 4.34 & $2.92-6.45$ \\
\hline \multicolumn{6}{|l|}{ Paid work leave } \\
\hline No & 69.0 & 7.6 & 0.305 & 1.00 & \\
\hline Yes & 31.0 & 2.7 & & 0.33 & $0.03-3.51$ \\
\hline \multicolumn{6}{|l|}{ Occupational disease-related work leave } \\
\hline No & 53.8 & 4.5 & 0.002 & 1.00 & \\
\hline Yes & 46.2 & 28.3 & & 8.47 & $1.93-37.13$ \\
\hline \multicolumn{6}{|l|}{ Time of work leave } \\
\hline Up to 15 days & 9.6 & 10.1 & 0.347 & 1.00 & \\
\hline More than 15 days and less than 3 months & 33.5 & 18.5 & & 2.01 & $0.37-10.86$ \\
\hline 3 months and more & 56.9 & 10.2 & & 1.01 & $0.18-5.65$ \\
\hline \multicolumn{6}{|l|}{ How many jobs } \\
\hline None & 39.5 & 1.9 & $<0.001$ & 1.00 & \\
\hline One & 57.9 & 2.8 & & 1.47 & $1.18-1.83$ \\
\hline Two or more & 2.6 & 5.0 & & 2.73 & $1.69-4.39$ \\
\hline \multicolumn{6}{|l|}{ Work at night hours } \\
\hline No & 85.3 & 2.8 & 0.568 & 1.00 & \\
\hline Yes & 14.7 & 3.1 & & 1.10 & $0.79-1.55$ \\
\hline \multicolumn{6}{|l|}{ Works on environments } \\
\hline Closed & 52.3 & 3.7 & $<0.001$ & 1.00 & \\
\hline Open & 27.5 & 1.5 & & 0.38 & $0.28-0.53$ \\
\hline Both & 20.2 & 2.7 & & 0.71 & $0.52-0.95$ \\
\hline \multicolumn{6}{|l|}{ Exposure to noise at the workplace } \\
\hline No & 67.9 & 2.3 & $<0.001$ & 1.00 & \\
\hline Yes & 32.1 & 4.1 & & 1.79 & $1.43-2.24$ \\
\hline \multicolumn{6}{|l|}{ Seniority at the current job ${ }^{b}$} \\
\hline Up to 4.5 years & 49.9 & 2.4 & 0.005 & 1.00 & \\
\hline More than 4.5 years & 50.1 & 3.3 & & 1.37 & $1.10-1.72$ \\
\hline
\end{tabular}

WMSD: work-related musculoskeletal disorders.

a Pearson's Chi-square test.

${ }^{\mathrm{b}}$ Median $=4.5$ years. 
Table 3. Univariate analysis assessing personal resources and health conditions associated with the occurrence of WMSD, according to data from the PNS, Brazil, 2013.

\begin{tabular}{|c|c|c|c|c|c|}
\hline Variable & Percentage (\%) total sample & Prevalence (\%) of WMSD & $\mathrm{p}^{*}$ & OR & $95 \% \mathrm{Cl}$ \\
\hline \multicolumn{6}{|c|}{ Participated in sport or artistic activities } \\
\hline No & 74.6 & 2.3 & 0.020 & 1.00 & \\
\hline Yes & 25.4 & 3.0 & & 1.27 & $1.04-1.56$ \\
\hline \multicolumn{6}{|c|}{ Participated in neighborhood association } \\
\hline No & 84.0 & 2.4 & 0.028 & 1.00 & \\
\hline Yes & 16.0 & 3.0 & & 1.27 & $1.03-1.57$ \\
\hline \multicolumn{6}{|l|}{ Participated in volunteer work } \\
\hline No & 87.9 & 2.2 & $<0.001$ & 1.00 & \\
\hline Yes & 12.1 & 4,7 & & 2.20 & $1.74-2.78$ \\
\hline \multicolumn{6}{|c|}{ Participated in cults and religious activities } \\
\hline No & 29.6 & 1.7 & $<0.001$ & 1.00 & \\
\hline Yes & 70.4 & 2.9 & & 1.73 & $1.38-2.18$ \\
\hline \multicolumn{6}{|c|}{ Practiced some type of physical activity } \\
\hline No & 69.0 & 2.4 & 0.315 & 1.00 & \\
\hline Yes & 31.0 & 2.7 & & 1.11 & $0.90-1.38$ \\
\hline \multicolumn{6}{|l|}{ Reported health } \\
\hline Very good & 13.0 & 2.4 & 0.001 & 1.00 & \\
\hline Good & 52.5 & 2.1 & & 0.87 & $0.63-1.19$ \\
\hline Regular, poor and very poor & 34.6 & 3.1 & & 1.29 & $0.94-1.77$ \\
\hline \multicolumn{6}{|c|}{ Diagnosis of arthritis or rheumatism } \\
\hline No & 93.3 & 2.2 & $<0.001$ & 1.00 & \\
\hline Yes & 6.7 & 6.3 & & 2.96 & $2.31-3.81$ \\
\hline \multicolumn{6}{|l|}{ Diagnosis of depression } \\
\hline No & 92.1 & 2.1 & $<0.001$ & 1.00 & \\
\hline Yes & 7.9 & 7.3 & & 3.67 & $2.96-4.55$ \\
\hline \multicolumn{6}{|l|}{ Uses medication to sleep } \\
\hline No & 92.0 & 2.3 & $<0.001$ & 1.00 & \\
\hline Yes & 8.0 & 4.9 & & 2.22 & $1.72-2.87$ \\
\hline
\end{tabular}

WMSD: work-related musculoskeletal disorders.

* Pearson's Chi-square test.

Table 4. Multivariate analysis (binary logistic regression model) assessing factors associated with the occurrence of WMSD, according to data from the PNS, Brazil, 2013.

\begin{tabular}{|c|c|c|c|}
\hline Variable & p* & OR & $95 \% \mathrm{Cl}$ \\
\hline \multicolumn{4}{|l|}{ Sex } \\
\hline Male & & 1.00 & \\
\hline Female & $<0.001$ & 2.33 & $1.72-3.15$ \\
\hline \multicolumn{4}{|l|}{ Marital status } \\
\hline Have a partner & & 1.00 & \\
\hline No partner & 0.006 & 0.73 & $0.58-0.91$ \\
\hline \multicolumn{4}{|c|}{ Temporary leave from work } \\
\hline No & & 1.00 & \\
\hline Yes & 0.001 & 2.44 & $1.41-4.23$ \\
\hline \multicolumn{4}{|l|}{ Works on environments } \\
\hline Closed & & 1.00 & \\
\hline Open & $<0.001$ & 0.51 & $0.37-0.71$ \\
\hline Both & 0.139 & 0.78 & $0.56-1.08$ \\
\hline \multicolumn{4}{|c|}{ Exposure to noise at the workplace } \\
\hline No & & 1.00 & \\
\hline Yes & $<0.001$ & 2.16 & $1.68-2.77$ \\
\hline \multicolumn{4}{|c|}{ Seniority at the current job } \\
\hline Up to 4.5 years & & 1.00 & \\
\hline More than 4.5 years & 0.007 & 1.37 & $1.09-1.72$ \\
\hline \multicolumn{4}{|c|}{ Participated in volunteer work } \\
\hline No & & 1.00 & \\
\hline Yes & $<0.001$ & 1.65 & $1.25-2.17$ \\
\hline \multicolumn{4}{|c|}{ Diagnosis of arthritis or rheumatism } \\
\hline No & & 1.00 & \\
\hline Yes & $<0.001$ & 2.40 & $1.68-3.44$ \\
\hline \multicolumn{4}{|l|}{ Diagnosis of depression } \\
\hline No & & 1.00 & \\
\hline Yes & $<0.001$ & 2.48 & $1.86-3.31$ \\
\hline
\end{tabular}

WMSD: work-related musculoskeletal disorders.

* Hosmer and Lemeshow goodness of fit statistics $=0.962$. 
Regarding the characteristics of the sample, women prevailed (55.1\% of respondents); $27.1 \%$ were aged 55 years or more; $54.5 \%$ did not have a partner; and $35.5 \%$ reported having elementary education level. In relation to occupational characteristics and working conditions, $56.9 \%$ of the respondents were paid in money; $0.2 \%$ with products or services; $1.8 \%$ had "odd jobs" or worked occasionally; and $0.8 \%$, despite working, were not paid. About work leaves, $1.5 \%$ were temporarily away (of these, $31.0 \%$ were provided with benefits); $46.2 \%$ were related to an occupational disease; and $56.9 \%$ for a period of three months or more. The category "having more than one job" was reported by $2.6 \%$ of Brazilians and, of these, $14.9 \%$ worked at night; $52.3 \%$ in closed environments; and $32.1 \%$ were exposed to noise in the workplace. As for seniority, the median was 4.5 years.

As for personal resources and health conditions, $25.4 \%$ of respondents reported participating in sport or artistic activities, $16 \%$ participated of neighborhood association, $12.1 \%$ practiced volunteer work, and $70.4 \%$ attended cults and religious celebrations. The prevalence of the practice of physical activity was of $31.0 \%$. The majority (52.5\%) of the Brazilians assessed their health as good. The prevalence of arthritis or rheumatism was $6.7 \%$, while depression was $7.9 \%$. Of the total of respondents, $8.0 \%$ reported using medication to sleep.

According to the univariate analysis, sociodemographic factors (Table 1) associated with higher prevalence of WMSD were: female sex, age ranging from 25-54 years, living without a partner, and higher education level ( $\mathrm{p}<0.05)$. Regarding occupational factors (Table 2$)$, those that were significantly associated with greater chance of occurrence of WMSD were: to inform work paid in money, be temporarily away (due to occupational disease), have two or more jobs, work in closed environments, be exposed to noise at work, and seniority equal to or greater than 4.5 years. As for personal resources and health conditions (Table 3 ) associated with a greater likelihood of WMSD $(\mathrm{p}<0.05)$, the following factors were identified: participate in sport or artistic activities, participate in neighborhood association, participate in volunteer work or cults or religious activities, report regular or poor health condition, report diagnosis of arthritis or rheumatism and depression, and use medication to sleep.

According to the final model of the multivariate analysis (Table 4), the factors associated with a greater chance of occurrence of WMSD were: female sex; be exposed to noise at the workplace; seniority equal to or greater than 4.5 years at the current job; participating in volunteer work; report medical diagnosis of arthritis or rheumatism and depression. Two factors associated with less chance of WMSD stood out: not having a partner and working in an open environment. It should be noted that the model presented good fit according to Hosmer and Lemeshow statistics $(\mathrm{p}=0.962)$.

\section{DISCUSSION}

PNS is the first nationwide study to investigate the self-reported prevalence of an occupational disease. WMSD stands out in the ranking of reasons that lead adult workers in Brazil, as well as in other industrialized countries, to miss work days and be disabled.

Sex, seniority in current work equal to or greater than 4.5 years, temporary leave from work, report of exposure to noise at the workplace, participation in voluntary unpaid work, report having been diagnosed with arthritis by a physician, and report having been diagnosed with depression by a mental health professional have been associated with a greater chance of occurrence of WMSD. Living without a partner and working in open environment decreased the chances of occurrence of the disorders.

The disease was reported by $2.5 \%$ of respondents in Brazil, varying from $0.2 \%$ to $4.2 \%$. It is not possible to establish comparisons ideals, because, although the results about the magnitude and the factors associated with musculoskeletal morbidities in specific populations are described, population-based studies that focused on musculoskeletal illness specifically related to work are rare. 
Verifying the prevalence differences when comparing the Brazilian states provides an opportunity for discussing the social inequalities and the geographical distribution of health services in the Country, which affect access to care. It is possible that the residents of the North and Northeast regions, where lower prevalence of WMSD was found, face access barriers when compared to the states of the other major regions, which would reflect on the self-reported diagnosis of WMSD and other morbidities.

In Brazil, similarly to other countries, the distribution of morbidity is characterized by social and geographic gradients. We observed that access to health services depends on where the individual lives, with advantage to regions with greater socioeconomic development ${ }^{9}$. The deployment of the Integral Care to Worker's Health Network (Renast) is the main strategy of SUS national policy on worker's health. Among the difficulties found for the consolidation of Renast, it is possible to mention its regionalized performance logic, different from SUS organization, which is city-based ${ }^{10}$, with possible reflections on information and registration of morbid events.

Other direction is possible to interpret the regional differences in the self-report of WMSD. The unequal offer of SUS services in the national territory is proved, with losses to lower-income groups, which coincide with the portions of the population inhabiting municipalities struggling to fulfill their responsibilities in the financing and provision of health services. The restrictions of the most poor individuals in paying for additional assistance reinforces the hypothesis about the effects of income distribution on access to care, increasing the likelihood of bias of information as to the diagnosis of morbidities ${ }^{11}$.

Despite the possibility of underestimation of self-reported information, WMSD is a framework originally described according to its relationship with work. It is plausible to assume that the answer to the question that generated the outcome variable leaves little margin for subtext, thus decreasing the likelihood of information bias. On the other hand, if the information bias is less likely, the same cannot be said about the controversies ${ }^{3}$ in terms of the occupational-clinical evaluation that would have accentuated the tendency toward underestimation of the studied prevalence. The controversy originates in the multifactorial nature of the disorders, particularly concerning the weight of individual factors. The dissent is enhanced by the existence of clinical profiles of distinct nature, patients who do not show objective signs when examined, and failures when the approach is made by only one physician, instead of by a multidisciplinary team.

Generally, the specific cases, whose pain is located and confirmed by examination using the known provocative tests (carpal tunnel syndrome, tenosynovitis, and impingement syndrome), are diagnosed in the first consultation. The cases raise controversy when the pain is apparently not explained by detectable injury or is associated with an injury that, in theory, would be insufficient to explain the intensity of the symptom. The greater chance of WMSD related to the information of being in a temporary work leave increases the consistence of the presented results. It is known that these disorders are incapacitating ${ }^{7,12}$.

The social iatrogenesis caused by the judiciary system when benefiting patients in cases of labor lawsuits, by Union militancy that encourages such measures, and by health systems that are "susceptible" to the diagnosis is being discussed ${ }^{13}$. Acting in this way, society would be feeding the polymorph clinical picture of patients who have a profile of making multiple complaints. The possibility of social iatrogenesis ( fairly widespread in Australia) achieved a broad repercussion in Brazil. Verthein and Gomez $(2001)^{14}$ exposed a substantiated criticism to what they called "the discursive bases of the neuropsychiatrization of RSI." According to the authors, the iatrogenic ideas of disease and the simulation of patients serve to set up a network of alliances formed to deny the nexus. In this context, once again, it is plausible to assume that the prevalence found in the Brazilian population is underestimated.

In general, the effects of gender differentials ${ }^{15}$ when examining the prevalence of musculoskeletal disorders in the general population and in specific occupational groups are well documented. Social roles assigned to men and women affect time management: women occupy themselves with household tasks at the expense of their personal interests, while men 
develop sports and leisure activities in their free time ${ }^{16}$. In addition, the working conditions of men and women are not equal, i.e., the effects of working life are more pronounced for women because they are more vulnerable to precarious employment, receive lower wages, have lower level positions in the hierarchy, as well as lower social recognition ${ }^{15}$. Arguments in the biological and behavioral plan, as differences in height, muscle strength, aerobic capacity, hormonal conditions, among others, would make a woman more susceptible to musculoskeletal disorders. However, the excessive prevalence in women of musculoskeletal pain in upper limbs was explained by increased exposure to risk factors in work and household environments, to the detriment of women's biological vulnerability to the mentioned risks ${ }^{17}$.

The arguments mentioned above can be evoked to explain the smaller chance of occurrence in the group living without a partner, since household tasks would be more likely in life as a couple, sometimes with children, and the resulting care for this situation. Family bonds offer support by sharing emotions, but can generate an accumulation, given the vicissitudes faced by spouses ${ }^{17}$. It is valid to remember that the effects of the work overload may add to the weight of family responsibilities, thus restricting the necessary pauses for rest and recovery of musculoskeletal wear ${ }^{16}$.

The group of individuals with greater seniority in the job had more chance to report WMSD. Seniority is a marker of duration of exposure to occupational factors, which also favors the gaining of experience. On the other hand, a decrease in the capacity of adjusting the workload is expected, due to the accumulation of effects of environmental and psychosocial factors that individuals face along their professional career ${ }^{18}$. Therefore, the greater chance of WMSD in this group would not be unexpected.

As for the lesser chance of occurrence in the group who reported working in open environments, other information would be necessary to develop grounded hypotheses. Still, it is not unlikely that working in this condition is free of the injunctions that characterize the industrial production management methods, which expose individuals to the repetition of cadenced operations and poor autonomy, both well documented characteristics regarding their relationship with WMSD ${ }^{2,12}$.

Exposure to intense noise during labor activity increased the chance of occurrence of WMSD. This result is not surprising, since the association between musculoskeletal disorders and environmental factors are known ${ }^{19}$. Regarding noise, we can suggest the hypothesis of extra-auditory effects, such as irritation and discomfort ${ }^{20}$, which cause reactions at the muscle fibers. In situations of involuntary increase of myofibrils contraction, the microbreaks needed for muscle work decrease, with losses on the reperfusion of the peritendinous tissues. Inflammatory processes resulting from this situation would explain the symptoms of muscle fatigue, pain, and, if the environmental exposure is maintained, function limitation ${ }^{19}$.

The greatest chance of WMSD in the group who reported participating in volunteer work in the community is consistent with the inability that the pain situation provokes. If so, individuals who had limitations to keep their jobs would be available to act in other spheres of life, for example, community actions of voluntary character. Interdisciplinary research shows important pathways to understand the impact of an incapacitating occupational disease over the different dimensions of social life ${ }^{14}$.

As for the report of having been diagnosed with arthritis by a physician, the prevalence found (6.7\%) was lower than the results (18.53\%) collected by interviews in the households of southern Asia $^{21}$. It is possible that the difference is explained by the methodological strategy used in the PNS, whose question led to variable "evokes medical diagnosis." However, in both cases, the prevalence of the disease is high.

A population-based survey sought to identify the duration of comorbidities in the group that reported musculoskeletal disorders in the cervical and lower back regions ${ }^{22}$. The prevalence of arthritis along with isolated cervical pain and cervical pain simultaneously with low back pain was of $35.1 \%$ and $46.2 \%$, respectively, as opposed to the prevalence of $13.8 \%$ in the 
group that denied cervical and low back muscle pains. In agreement with the results from PNS, in the case of depressive symptoms, the same trend was verified: $23.9 \%$ and $40.1 \%$ of simultaneous self-reported prevalence, respectively, to isolated cervical pain and cervical pain along with low back pain ${ }^{22}$.

The maintenance of employment and work activity is a stimulated measure in rheumatological practice. Despite the benefits, the workplace can be a source of occupational stress ${ }^{23}$, having negative effects on the situation of individuals suffering from these rheumatic morbidities. We observed that the expected protective effect of labor activity on the evolution of the symptoms of arthritis was frustrated when the individuals were exposed to tasks for which they had restricted control margins (opening to choose when and how to perform the tasks), as opposed to high demands (volume of tasks, speed with which they should be finished, and time available to meet these requirements). These work-related tensions can be expressed as greater or lesser job satisfaction, and these experiences can lead to stressful events, which interact with the physical and mental health of the individual, thus worsening rheumatic and depression symptoms. In this sense, the PNS results that indicate these comorbidities are plausible.

Depression is an independent risk factor for a set of musculoskeletal disorders ${ }^{24}$. According to the hypothesis of cognitive vulnerability, stressful events tend to precipitate depressive situations ${ }^{25}$. The multifactorial character, as well as the role of psychosocial factors (such as dissatisfaction) in the development of musculoskeletal disorders and psychiatric comorbidities are very clear, both in the triggering and worsening of chronic musculoskeletal pain, which is the main symptom of WMSD ${ }^{26}$.

However, the proposed hypotheses do not allow more incursions. The report of diagnosis of depression can be associated with the investigated outcome. It is also possible, however, that the experiences related to an occupational disease are exacerbating pre-existing problems, or that they are more easily noticed by people with depressive profiles and, therefore, are more often reported by them.

The limits derived from the lack of methodological consensus indicate caution in interpreting the results. The definition of the event to characterize the outcome varies in current literature, with losses to attempts at comparison of the obtained results. It is possible to question about complaints ${ }^{5-8,12,17,22}$; or diagnosis ${ }^{21}$; to investigate musculoskeletal morbidities in general the group of workers active in a particular branch of production ${ }^{6-8,12}$; or interview employed individuals in their households ${ }^{21}$, as is also the case of PNS.

The macroeconomic structure, the internationalization of investment, and the application of new technologies can transform the policies of employment and working conditions. Considering the weakening of Union power and unemployment, the productive restructuring environment becomes conducive to the implementation of management strategies that increase stressful situations (absence of pauses, demand for more parts per unit of time, for example), as well as generate new forms of insertion of individuals on production ${ }^{12,15}$. In this context, the sources of information on employment, work, and health of workers become even more precarious. For the first time in Brazil, it was possible to examine the prevalence of a disease of such importance for the already discussed reasons. Memory bias, differences in estimates of illness, and inadequacy of resources to assess the quality of data collection are inherent limitations to investigations. However, the contribution of this kind of study to improve quality of care is undeniable, being thus possible to enhance programs and evaluate the policies specific to occupational groups.

In addition, it is worth noting that the statistical analysis benefited from the advantages concerning the expressive sampling size, as well as the high response rate. The sampling design of the PNS, as well as the weights used in the analysis, ensures data representativeness for Brazil, its major regions, states, metropolitan areas, capital cities and other municipalities, thus allowing an accurate characterization of the health conditions of the Brazilian population. It is known that the prevalence measures of occupational diseases are a 
challenge for the countries where health information systems of workers do not cover the total employed population or presents vices related to the exclusive coverage of the formally employed population, as is Brazil's case.

The results indicate the need to monitor comorbidities in the case of musculoskeletal diseases, and strengthen programs focused on gender differentials. Special attention environmental noise monitoring would benefit the health of workers in the Country.

\section{REFERENCES}

1. Costa BR, Vieira ER. Risk factors for work-related musculoskeletal disorders: a systematic review of recent longitudinal studies. Am J Ind Med. 2010;53(3):285-323. https://doi.org/10.1002/ajim.20750.

2. Ha C, Roquelaure YC, Leclerc AA, Goldberg M, Imbernon E. The French Musculoskeletal Disorders Surveillance Program: Pays de la Loire network. Occup Environ Med. 2009;66(7):471-9. https://doi.org/10.1136/2oem.2008.042812.

3. Helliwell PS, Taylor WJ. Repetitive strain injury. Postgrad Med J. 2004;80(946):438-43. https://doi.org/10.1136/pgmj.2003.012591.

4. Bevan S. Economic impact of musculoskeletal disorders (MSDs) on work in Europe. Best Pract Res Clin Rheumatol. 2015;29(3):356-73. https://doi.org/10.1016/j.berh.2015.08.002.

5. Gerr F, Fethke N, Merlino L, Anton D, Rosecrance J, Jones MP, et al. A prospective study of musculoskeletal outcomes among manufacturing workers: I. effects of physical risk factors. Hum Factors. 2014;56(1):112-30. https://doi.org/10.1177/0018720813491114.

6. Brandão AG, Horta BL, Tomasi E. Sintomas de distúrbios osteomusculares em bancários de Pelotas e região: prevalência e fatores associados. Rev Bras Epidemiol. 2005;8(3):295-305. https://doi.org/10.1590/S1415-790X2005000300011.

7. Picoloto D, Silveira E. Prevalência de sintomas osteomusculares e fatores associados em trabalhadores de uma indústria metalúrgica de Canoas-RS. Cienc Saude Coletiva. 2008;13(2):507-16. https://doi.org/10.1590/S1413-81232008000200026.

8. Barbosa REC, Assunção AA, Araújo TM. Distúrbios musculoesqueléticos em trabalhadores do setor saúde de Belo Horizonte, Minas Gerais, Brasil. Cad Saude Publica. 2012;28(8):1569-80. https://doi.org/10.1590/S0102-311X2012000800015.

9. Travassos C, Oliveira EXG, Viacava F. Desigualdades geográficas e sociais no acesso aos serviços de saúde no Brasil: 1998 e 2003. Cienc Saude Coletiva. 2006;11(4):975-86. https://doi.org/10.1590/S1413-81232006000400019.

10. Dias EC, Hoefel MG. O desafio de implementar as ações de saúde do trabalhador no SUS: a estratégia da RENAST. Cienc Saude Coletiva. 2005;10(4):817-27. https://doi.org/10.1590/S1413-81232005000400007.

11. Cambota JN, Rocha FF. Determinantes das desigualdades na utilização de serviços de saúde: análise para o Brasil e regiões. Pesq Planej Econ. 2015;45(2):219-43.

12. Fernandes RCP, Carvalho FM, Assunção AA. Prevalence of musculoskeletal disorders among plastics industry workers. Cad Saude Publica. 2011;27(1):78-86. https://doi.org/10.1590/S0102-311X2011000100008.

13. Bell DS. Repetition strain injury: an iatrogenic epidemic of simulated injury. Med I Aust. 1989;151(5):280-4.

14. Verthein MAR, Gomez CM. As armadilhas: bases discursivas da neuropsiquiatrização das LER. Cienc Saude Coletiva. 2001;6(2):457-70. https://doi.org/10.1590/S1413-81232001000200015.

15. Hirata H, Kergoat D. Novas configurações da divisão sexual do trabalho. Cad Pesq. 2007;37(132):595-609. https://doi.org/10.1590/S0100-15742007000300005.

16. Arcas MM, Novoa AM, Artazcoz L. Gender inequalities in the association between demands of family and domestic life and health in Spanish workers. Eur J Public Health. 2013;23(5):883-8. https://doi.org/10.1093/eurpub/cks095.

17. Wijnhoven HAH, Vet HCW, Picavet HSJ. Prevalence of musculoskeletal disorders is systematically higher in women than in men. Clin J Pain. 2006;22(8):717-24. https://doi.org/10.1097/01.ajp.0000210912.95664.53. 
18. Chau N, Bhattacherjee A, Kunar BM. Relationship between job, lifestyle, age and occupational injuries. Occup Med (Lond). 2009;59(2):114-9. https://doi.org/10.1093/occmed/kqp002.

19. Magnavita N, Elovainio M, De Nardis I, Heponiemi T, Bergamaschi A. Environmental discomfort and musculoskeletal disorders. Occup Med (Lond). 2011;61(3):196-201. https://doi.org/10.1093/occmed/kqr024.

20. Basner M, Babisch W, Davis A, Brink M, Clark C, Janssen S, et al. Auditory and non-auditory effects of noise on health. Lancet. 2014;383(9925):1325-32. https://doi.org/10.1016/S0140-6736(13)61613-X.

21. Levesque JF, Mukherjee S, Grimard D, Boivin A, Mishra S. Measuring the prevalence of chronic diseases using population surveys by pooling self-reported symptoms, diagnosis and treatments: results from the World Health Survey of 2003 for South Asia. Int J Public Health. 2013;58(3):435-47. https://doi.org/10.1007/s00038-013-0446-5.

22. Strine TW, Hootman JM. US national prevalence and correlates of low back and neck pain among adults. Arthritis Rheum. 2007;57(4):656-65. https://doi.org/10.1002/art.22684.

23. Griep RH, Rotenberg L, Landsbergis P, Vasconcellos-Silva PR. Uso combinado de modelos de estresse no trabalho e a saúde auto-referida na enfermagem. Rev Saude Publica. 2011;45(1):145-2. https://doi.org/10.1590/S0034-89102011000100017.

24. Magni G, Moreschi C, Rigatti-Luchini S, Merskey H. Prospective study on the relationship between depressive symptoms and chronic musculoskeletal pain. Pain.1994;56(3):289-97. https://doi.org/10.1016/0304-3959(94)90167-8

25. Alloy LB, Abramson LY, Whitehouse WG, Hogan ME,Tashman NA, Steinberg DL, et al. Depressogenic cognitive styles: predictive validity, information processing and personality characteristics, and developmental origins. Behav Res Ther. 1999;37(6):503-31. https://doi.org/10.1016/S0005-7967(98)00157-0.

26. Menzel NN. Psychosocial factors in musculoskeletal disorders. Crit Care Nurs Clin North Am. 2007;19(2):145-53. https://doi.org/10.1016/j.ccell.2007.02.006.

Authors' Contribution: Study design and development of the first version of the article: AAA. Data analysis: MNSA. Data interpretation and review and approval of the final version to be published: AAA, MNSA.

Conflict of Interest: The authors declare no conflict of interest. 